\title{
TRANSFORMATIONS OF CARBOXONIUM COMPOUNDS IN CARBOHYDRATE AND POLYOL CHEMISTRY
}

\author{
Hans Paulsen \\ Institute of Organic Chemistry and Biochemistry, University of Hamburg, \\ GFR
}

\begin{abstract}
By attaching 1,3-dioxolenium or 1,3-dioxenium rings to polyfunctional compounds, cationic species are obtained which are prone to undergo several different transformations, such as 1,2- and 1,3-neighbouring group reactions as well as ring contraction reactions. The synthesis and characterization of such carboxonium ions is discussed. In a series of monosaccharides and also polyols the enhanced reactivity of carboxonium ions is the reason for manifold rearrangements.
\end{abstract}

During the last 10 years it has been possible to find conditions under which more or less free carbenium ions with an enhanced lifetime can be synthesized. In this connection one first of all thinks of reactions in super acids studied by Olah ${ }^{1}$ and his collaborators. These studies have demonstrated that free carbenium ions are rather reactive and often undergo extremely fast carbon skeletal rearrangements to yield more stable carbenium ions. Naturally these investigations were only possible in the range of the rather stable hydrocarbons and not in the field of polyfunctional compounds. However, by resonance stabilization of the cationic centre with one or several hetero atoms the reactivity of the resulting cation can gradually be lowered. This kind of stabilized cation can be obtained with polyfunctional compounds. There, the reactivity is lowered so far that uncontrolled degradations are excluded but is still high enough to give rise to interesting and directed rearrangements. The purpose of this lecture will be to show you how carefully this line -that is between too 'hot' and too 'cold' cations- must be manipulated in order to control the manifold applications of transformations of polyfunctional compounds.

Particularly suitable cations are represented by the carboxonium ions which are resonance-stabilized by two oxygen atoms. These are ions of the dioxolenium type, as shown in Figure 1. More simply, such an ion related to a carbonic acid can be named acyloxonium ion -in this case acetoxonium ion-related to acetic acid. It was Meerwein ${ }^{2.3}$ who first succeeded in isolating crystalline acyloxonium salts.

The general methods by which acyloxonium ions can be generated have been summarized in Figure 1. As shown here, the acetoxonium ion, for 


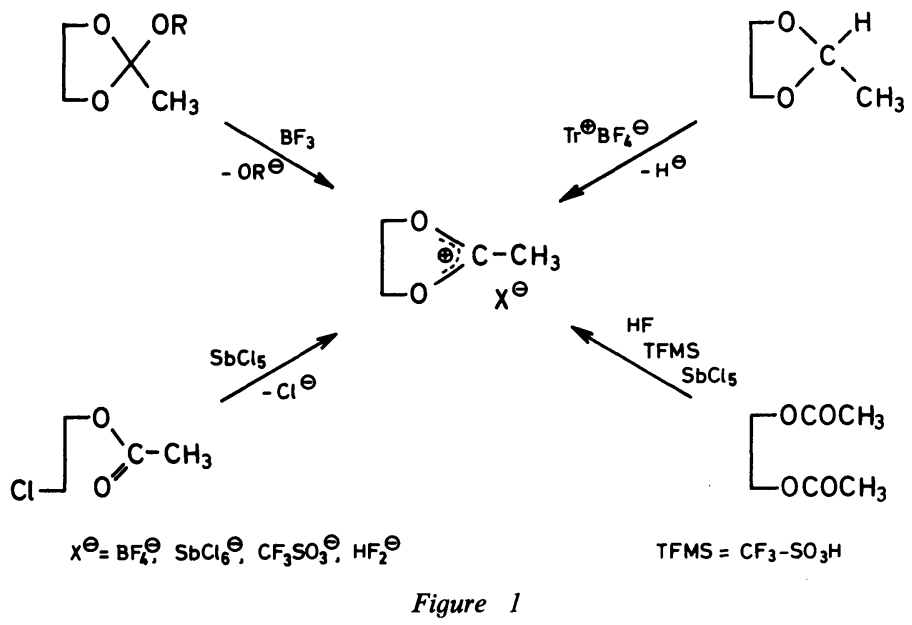

example, can be obtained by splitting off alkoxylate from orthoesters ${ }^{2,3}$ and eliminating hydride from aldehydacetals, as well as by neighbouring group reactions caused by reaction of antimony pentachloride on halohydrinesters or diol esters ${ }^{4,5}$. Furthermore, strong acids such as liquid hydrogen fluoride 6 or trifluoromethane sulphonic $\mathrm{acid}^{7}$ open up a direct transformation of the diol ester to this cation.

In Figure 2 the steric requirements for the cause of this reaction are shown. By application of hydrogen fluoride only cis-diol esters react ${ }^{6}$ with antimony pentachloride; however, as a rule the trans-diol esters ${ }^{5}$ react by neighbouring group reactions. Both these reagents are exceeded in reactivity by trifluoromethane sulphonic acid. By use of this latter reagent quite generally cis- as well as trans- diol esters can be transformed to acyloxonium ions?

It has to be indicated that the splitting reaction by which acyloxonium ions are generated is subject to certain selective controls. With mixed esters (Figure 3) in the cis- as well as in the trans- reaction, that acid residue is split off which can form the most stable acylium cation or the most stable protonated acid ${ }^{8,9}$. For example, with cis- and trans-1-acetoxy-2-p-nitrobenzoxycyclohexane (Figure 3 ) by both types of reactions the benzoxonium ion is obtained, because in both cases acetic acid is split off more easily ${ }^{8,9}$.

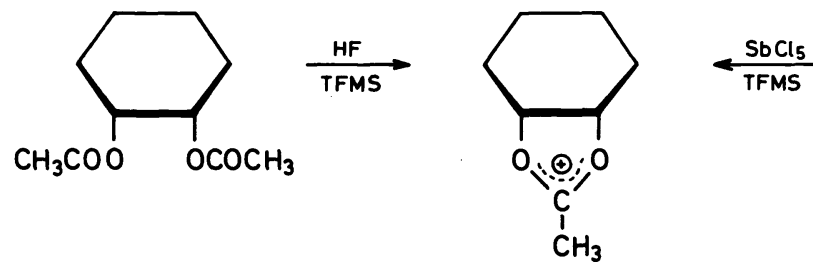

Figure 2

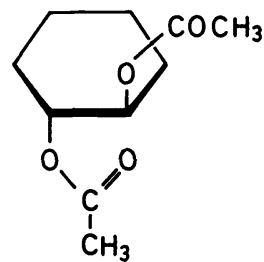

TFMS $=\mathrm{CF}_{3}-\mathrm{SO}_{3} \mathrm{H}$ 

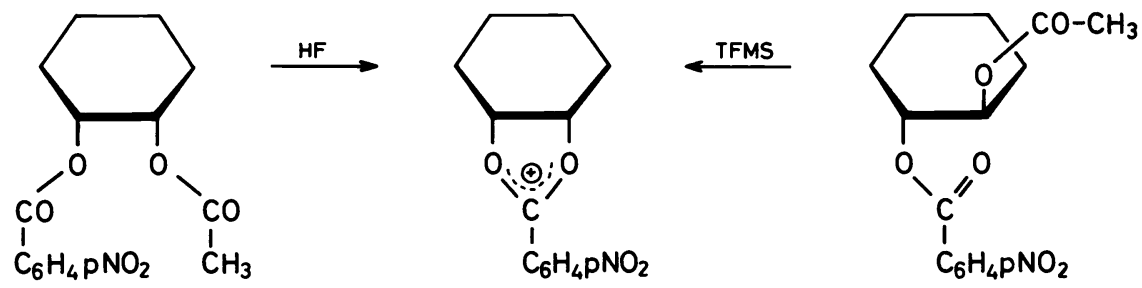

TFMS $=\mathrm{CF}_{3}-\mathrm{SO}_{3} \mathrm{H}$

Figure 3

A further selective control has been shown to occur with diol ester groupings, one of which is tertiary and bound to a branching point, e.g. the compound in Figure 4 having a primary acetoxy and a tertiary trideuteroacetoxy group. By application of the trans- reaction to this compound the preferred elimination of the tertiary group has been demonstrated ${ }^{10}$. In consequence of this, the configuration at the branching point is inverted, as shown in Figure 4. In the example under discussion the conformational equilibrium of the cation will be obtained finally. This reaction path opens up a way by which selective transformations can be accomplished at a branching point.
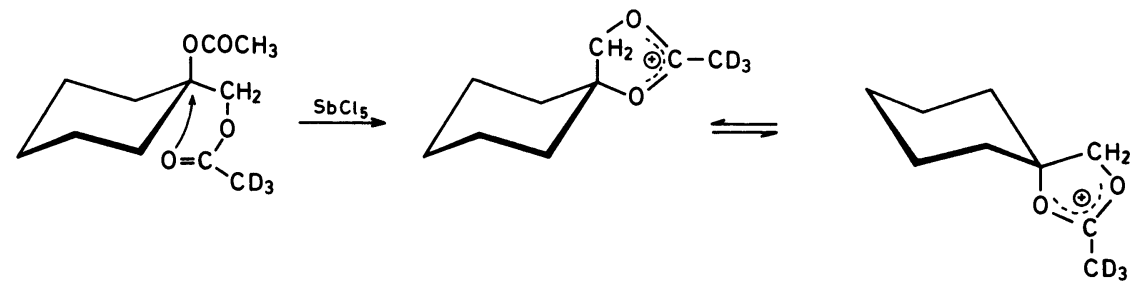

Figure 4

Of particular interest is the exact molecular structure of a dioxolenium ring, because this can be rather important for the stereochemical control of rearrangement reactions of the cation. In this connection, we carried out the $\mathrm{x}$-ray structure analysis of two acetoxonium perchlorates (Figure 5) ${ }^{11,12}$. Although hexachloroantimonates are more easily obtained, they proved to be of rather limited value for a crystal analysis. Consequently, as shown in Figure 5, the perchlorates were prepared, the recrystallization of which finally gave useful and stable enough single crystals.

The tetramethyldioxolenium compound (Figure 5, to the left) exhibits the structure shown in Figure 6 with a totally planar dioxolenium ring ${ }^{11}$. This result is most remarkable because it implies that in the molecule each pair of methyl groups are entirely eclipsed, showing a torsion angle of zero degrees. Obviously the resonance energy of the carboxonium system enforces a total flattening of the ring; it is more powerful than the energy resulting from the steric interactions of the twofold eclipsed positions of the four methyl groups. 


\section{HANS PAULSEN}<smiles>CC(C)(O)C(C)(C)O</smiles><smiles></smiles>

$$
\begin{aligned}
& \mathrm{HClO}_{6} \\
& \mathrm{AC}_{2} \mathrm{O}
\end{aligned}
$$

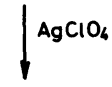<smiles>CC1(C)OC2(C)OC(C)(O2)C(C)(C)O1</smiles>

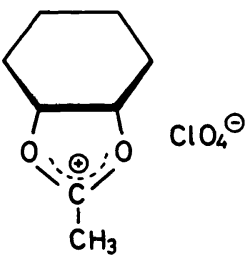

Figure 5

Provided that the dioxolenium ring in the acetoxonium salt of cyclohexanediol would also be completely planar, the cyclohexane ring would be expected to adopt a half-chair conformation, as in e.g. cyclohexene oxides. This is indeed the case, but partially, as shown in Figure 7. Deviation from planarity in the dioxolenium ring amounts to $25.9^{\circ}$, and furthermore the cyclohexane ring is only twisted towards a half-chair form ${ }^{12}$. This can be

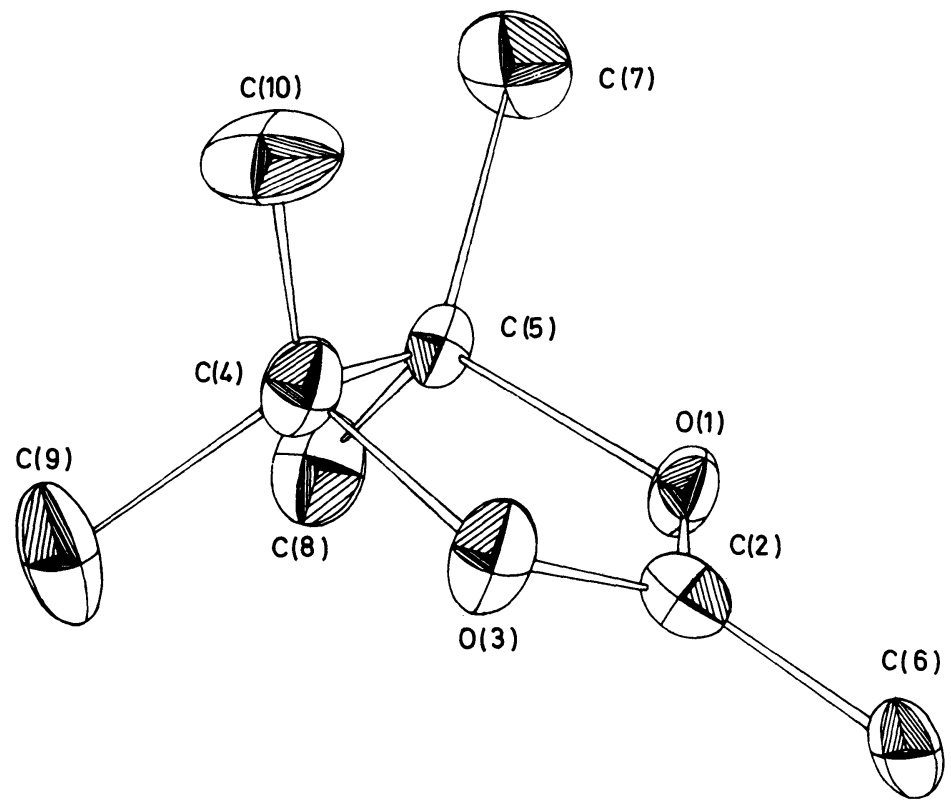

Figure 6 


\section{COMPOUNDS IN CARBOHYDRATE AND POLYOL CHEMISTRY}

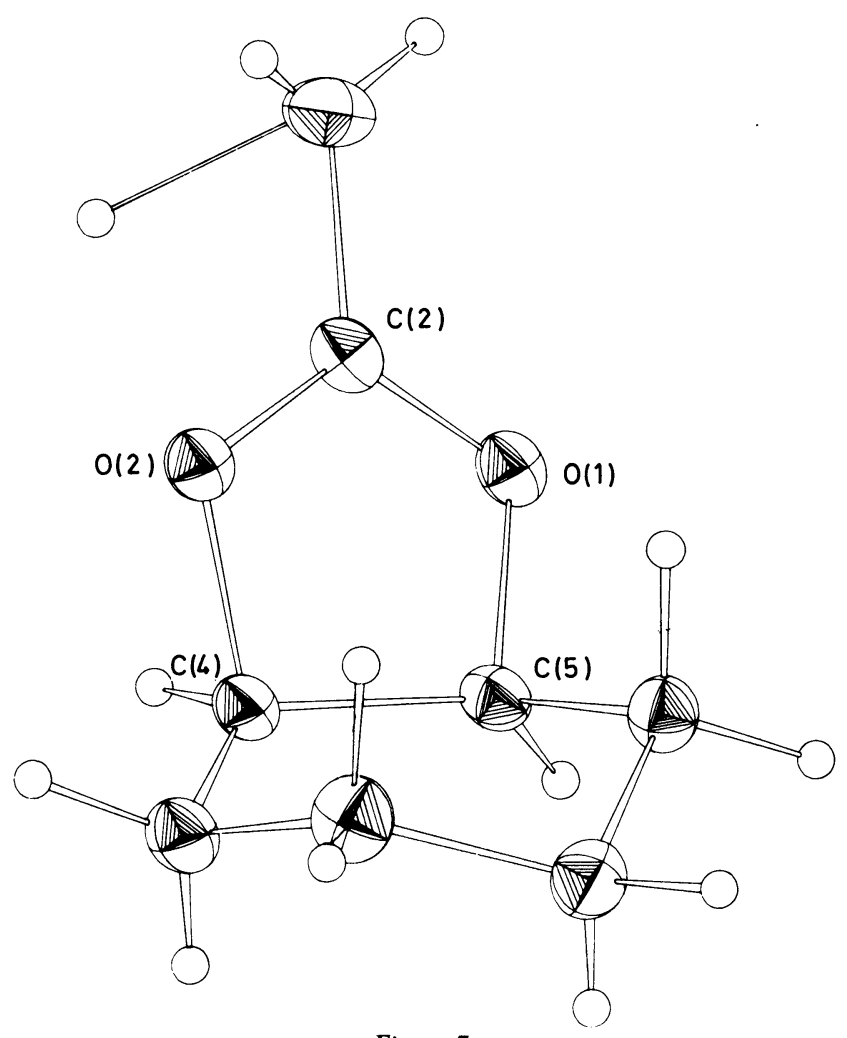

Figure 7

attributed to steric reasons. However, variable charge distributions have also been taken into account.

Figure 8 shows the bond lengths for both compounds ${ }^{11.12}$. The carbonoxygen bonds at the positively charged centre-that is, between $\mathrm{C} 2-\mathrm{O} 1$ and $\mathrm{C} 2-\mathrm{O} 3$, respectively-are considerably shortened. The distance is
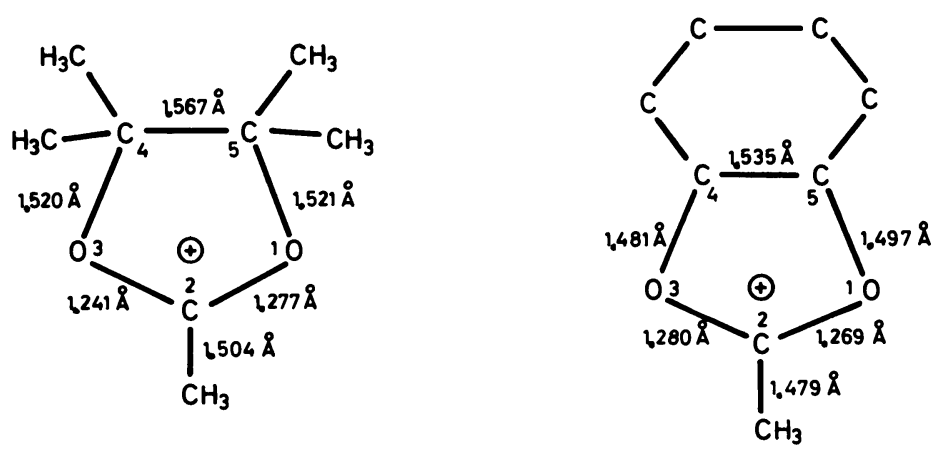

normal: $C-01.43 \AA \quad C=0.22 \AA \quad C-C 1.543 \AA$

Figure 8 


\section{HANS PAULSEN}

indeed shorter than a one-and-a-half double bond, which is in accord and expected for this three-atom resonance system. The other oxygen-carbon bonds between $\mathrm{O} 3-\mathrm{C} 4$ and $\mathrm{O} 1-\mathrm{C} 5$ are surprisingly extended, quite obvious in the tetramethyl compound (left). This supports the view that electrons of these bonds are attracted by the oxygen atoms. Furthermore, the electron-attracting effect is sustained by the electron-donating influence of the four methyl groups, which gives rise to the entirely planar dioxolenium ring. In the cyclohexane compound (to the right) the electron-donating effect of the ring methylene groups to $\mathrm{C4}$ and $\mathrm{C} 5$ is considerably lower, giving rise to an over-all less extended $\mathrm{O} 3-\mathrm{C} 4$ and $\mathrm{O} 1-\mathrm{C} 5$ bond. Supposedly the undisturbed mesomeric system cannot be formed, the dioxolenium ring is slightly twisted and the compound is notably more unstable, as has indeed been found. The results of ${ }^{13} \mathrm{C}$-n.m.r. spectra and e.s.c.a. spectra are in accord with these considerations ${ }^{12}$.

The following discussion will centre on the dynamics of acyloxonium ion reactions. If an acyloxonium compound contains further ester groups, these can react under rearrangement by an intramolecular trans- opening reaction ${ }^{13}$. Parts of two prototypes of such a 1,2-acyloxonium rearrangement are shown in Figure 9. It can be recognized that whenever the steric requirements are possible, the nucleophilic opening of the acyloxonium ring occurs easily by formation of a second ion which is in equilibrium with the former.

The rearrangement reaction proceeds surprisingly fast. The lifetime of the species is so short that in the n.m.r. spectrum the methyl signals of the acetoxonium group and the normal acetoxy group, which are separated at room temperature, coalesce to an average signal at elevated temperatures ${ }^{13}$. In both the examples shown the ions involved have the same structure,

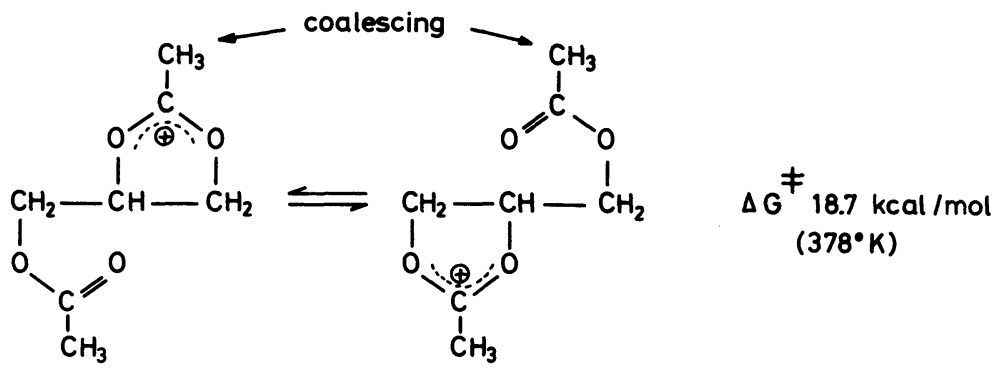
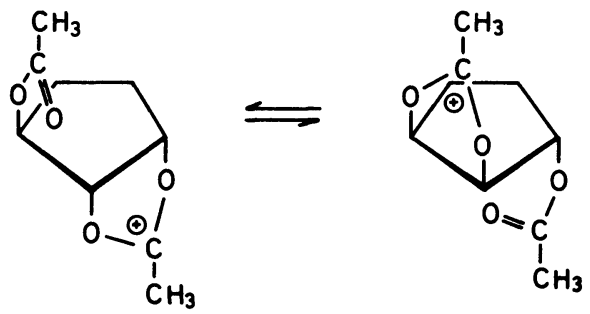

$\Delta G^{\ddagger} 18.0 \mathrm{kcal} / \mathrm{mol}$ $\left(365^{\circ} \mathrm{K}\right)$ 


\section{COMPOUNDS IN CARBOHYDRATE AND POLYOL CHEMISTRY}

which characterizes this process as a degenerated valence isomerism. The calculated $\Delta G^{\ddagger}$ values are in the range of $18 \mathrm{kcal} / \mathrm{mol}$ and amazingly low, because each single rearrangement step represents a real intramolecular $\mathrm{S}_{\mathrm{N}} 2$ reaction. This example indeed demonstrates the vast application of Winstein's concept of anchimeric assistance.
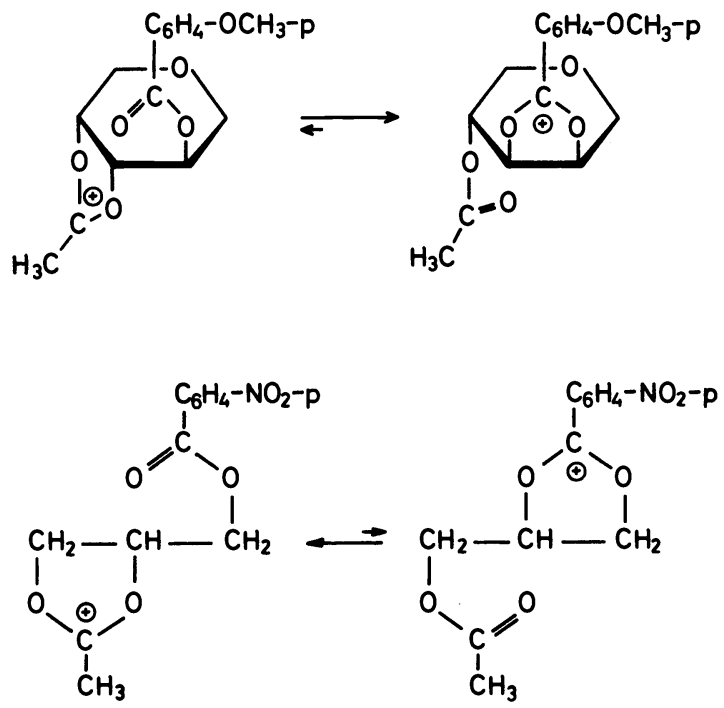

Figure 10

In the corresponding molecules with mixed ester groups (Figure 10) rearrangements are also observed; however, in this case the stability of the cations involved is different. Naturally the product distribution is in accord with the stability of the various cations. It could be shown that acyl residues containing electron-donating groups, such as $p$-methoxy phenyl, stabilize the corresponding acyloxonium ion. Thus the equilibrium is shifted largely to the more stable $p$-methoxy-benzoxonium ion ${ }^{14}$. On the other hand, electron-attracting groups destabilize the acyloxonium ion, which causes the second equilibrium (Figure 10) to be shifted almost entirely to the acetoxonium ion $^{9}$. These results are in accord with the expectation for cationic centres. By variations of acyl residues an important resource has been gained, by which acyloxonium rearrangements can be controlled selectively.

In the acetoxonium ion of cyclopentanepentol (Figure 11) we found some years ago an exceptional ion which in a series of consecutive 1,2- rearrangements participates in an over-all cyclic rearrangement process ${ }^{15}$. The stereochemistry in this case causes an ion of identical structure to be formed after each rearrangement step. Thus, after ten such consecutive rearrangement steps the starting cation will be formed again, which demonstrates the whole cyclo rearrangement. In fact, n.m.r. studies of this system support the cause of such a cyclic rearrangement. 

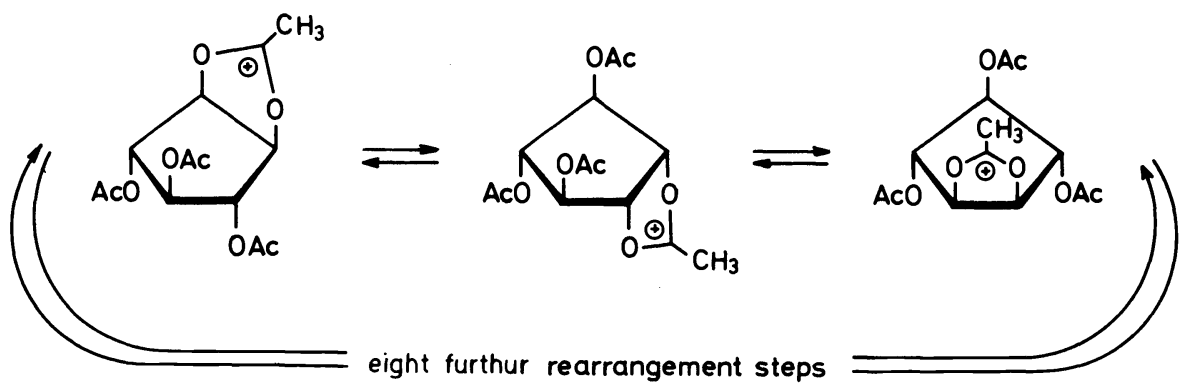

Figure 11

In addition to 1,2- rearrangements, 1,3- rearrangement steps can also be considered, in which one carbon is omitted ${ }^{16}$. Figure 12 (top line) shows the general type of such a 1,3- rearrangement, in which there is equilibrium between two dioxenium rings. Again in the n.m.r. spectrum coalescence of the two different methyl signals is observed at elevated temperature, and the $\Delta G^{\ddagger}$ value of this process is also approximately $18 \mathrm{kcal} / \mathrm{mol}^{16}$. Thus, this rearrangement occurs as easily as the one with the corresponding glycerine derivative. Dioxenium salts, however, are notably more unstable thermally than dioxolenium salts.

The enhanced stability of the five-membered ring is furthermore observed in the example in Figure 12 (bottom line). Here with a 1,2,4-butanetriol derivative a dioxenium and a dioxolenium ion are in equilibrium. It has been shown that the equilibrium is almost completely shifted to the five-membered<smiles>C=CCCC1OC(C)OCC[C@@H]1CCOC(C)=O</smiles><smiles>CC(=O)OCCC1CCOC(C)O1</smiles>

Figure 12 
ring ion, which is the only species observed in solution ${ }^{16}$. Thus, a simple method has been devised by which it was demonstrated that in unsubstituted compounds the five-membered ring ion is more stable than the six-membered ring ion.

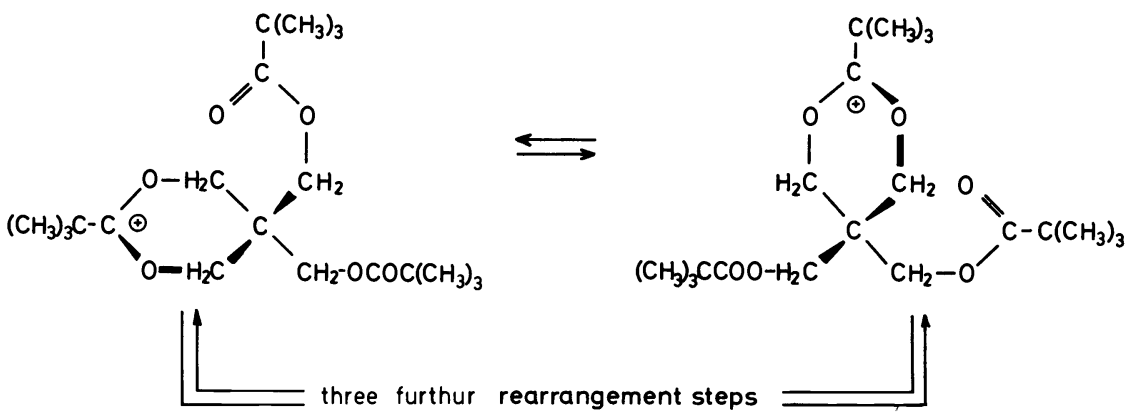

Figure 13

Furthermore, we have found a cyclo rearrangement in the series of 1,3rearrangements, as shown in Figure 13. The pivaloxonium salt of pentaerythritol, easily obtained by action of antimony pentachloride on pentaerythritol tetrapivalate, can rearrange to an ion of identical structure. Three further rearrangement steps, altogether four steps, yield the starting ion again. In this case coalescence is nicely observed in the n.m.r. spectrum, which unequivocally proves such a cyclo rearrangement. Interestingly, in this cyclo rearrangement the acyloxonium group moves around the central single tetrahedral carbon atom in spirals comparable to the motion of a universal joint.

Obviously 1,3- rearrangements do not cause any problems in open chain compounds. In cyclic compounds steric influences can change the situation. In Figure 14 a distinct reaction course is shown, in which the occurrence of 1,3- rearrangements in competition with 1,2- rearrangements can be demonstrated. In starting with acyloxonium compounds of optically active 1,2,3triols of the cyclopentane and cyclohexane series the same optical antipodes are always formed, only if a 1,2-acetoxonium rearrangement occurs ${ }^{17}$. Assuming only 1,2- rearrangements in the equilibration of the two ions, no racemization should be detected, as shown in Figure 9 (bottom line).

1,3- Rearrangement, however, should give rise to the formation of the enantiomeric form. The two cations on the left in Figure 14 clearly represent the optical antipodes of the two cations on the right. In the case of 1,3rearrangements the equilibration of the cations should lead to racemized products. Obviously, the course of the reaction is dependent primarily on the kind of counter-ion and secondarily on the ring size. Accordingly, a fast racemization is observed with cyclopentanetriol acetoxonium hexachloroantimonate (Figure 14, top line) ${ }^{17}$. With the same ion in liquid hydrogen fluoride, however, no racemization is observed even after extended reaction times ${ }^{17}$. With hexachloroantimonate and with trifluoromethane sulphonate 


\section{HANS PAULSEN}

as counter-ions, the acetoxonium salt of D-arabinitol (Figure 14, bottom line) shows a fast racemization ${ }^{17}$. In liquid hydrogen fluoride even after several days only up to ten per cent racemization was observed. Evidently, 1,3rearrangement steps occur more easily in the presence of hexachloroantimonate anions than in the presence of hydrogen difluoride anions, whereas trifluoromethane sulphonate anions show an average reactivity ${ }^{17}$.
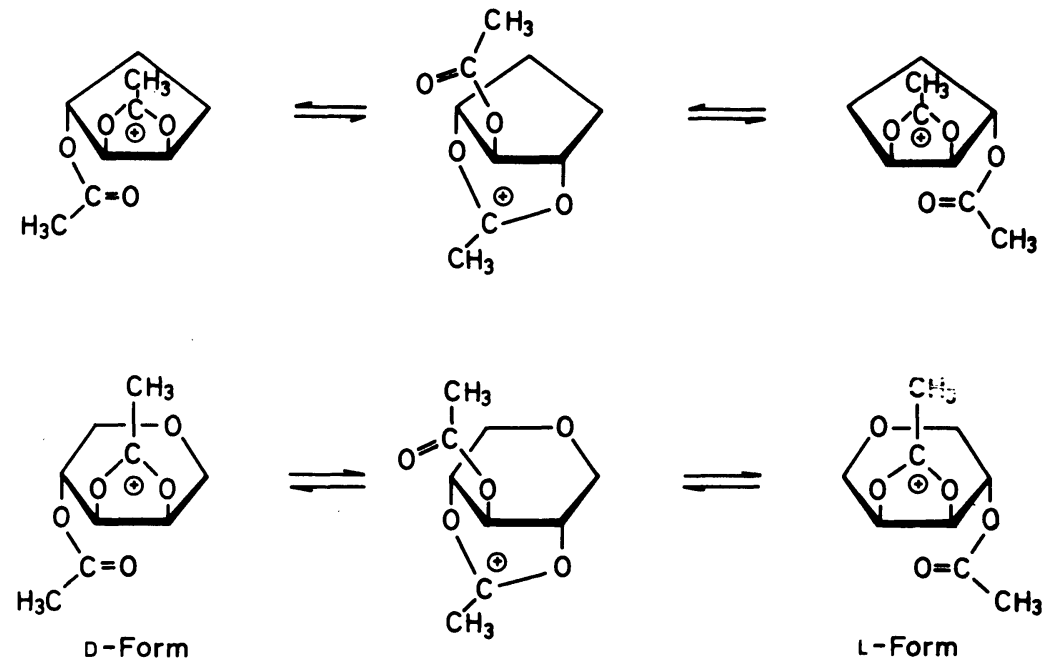

Figure 14

These results are in accord with other observations. The homogeneous crystalline pivaloxonium hexachloroantimony salt of cyclopentanetetrol (Figure 15, top line, left) could be prepared and was subjected to an equilibration reaction. In case only 1,2- rearrangement processes would be possible, nothing but the two isomeric cations of the top line (Figure 15) could be in equilibrium. As further isomers there is one (Figure 15, middle line, right), which cannot equilibrate by a 1,2- rearrangement, and the three isomers (Figure 15, bottom line) are in equilibrium. As shown in Figure 15, a transformation of the starting ion to the other isomers can only occur by 1,3rearrangement processes. The experiments show that even at low temperatures the 1,2- process can be detected. Since at room temperature all the five possible isomers occur in solution, when the experiment began with one pure isomer, this can only be explained by a 1,3- process which is markedly slower than the very fast 1,2- process. 1,3- Rearrangement steps with other isomeric cyclopentanetetroles in liquid hydrogen fluoride or by reaction with trifluoromethane sulphonic acid were determined only in minor amounts ${ }^{17}$.

In connection with isomerization experiments with acetic acid-sulphuric acid, Angyal and Luttrell ${ }^{18}$ made use of the cyclopentanepentol (Figure 16a). The isomerized mixture contained the three isomers of Figure 16, with isomer 16(c) predominating (72 per cent). Doubtless this isomerization is effected by an acetoxonium rearrangement. Via a 1,2-process the starting compound 


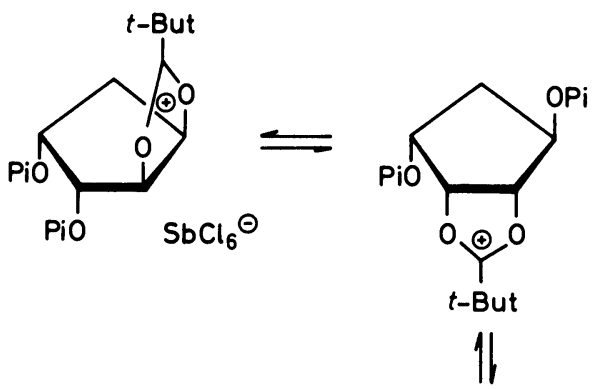

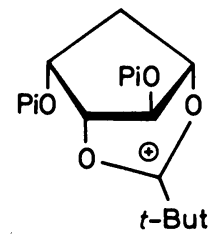

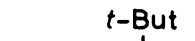

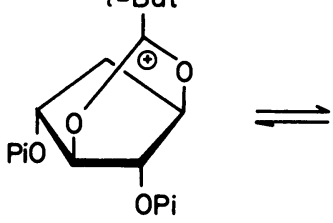

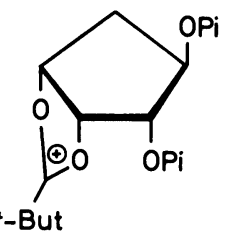<smiles>C=C=C</smiles>

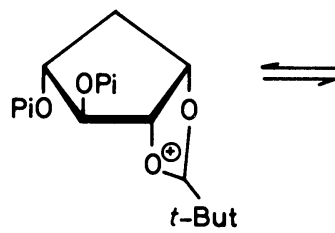

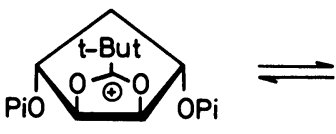

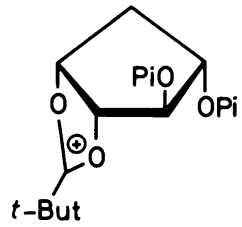

$\mathrm{Pi}=\left(\mathrm{CH}_{3}\right)_{3} \mathrm{CCO}-\quad t-\mathrm{But}=\left(\mathrm{CH}_{3}\right)_{3} \mathrm{C}-$

Figure 15

16(a) can only rearrange to the isomer $16(\mathrm{~b})$ with inversion of configuration at the marked carbon atom. The formation of the main compound, Figure 16(c), should proceed via a 1,3- process which operates here in the cyclopentane ring system.

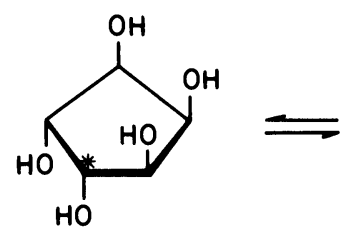

(a)

$17.5 \%$<smiles>OC1C(O)[C@H]2O[C@H](O)[C@H]1O2</smiles>

(b)<smiles>OC1C(O)[C@H](O)[C@H](O)[C@H]1O</smiles>

(c)

Figure 16 
<smiles>OC1C(O)[C@H](O)[C@@H](O)[C@@H](O)[C@H]1O</smiles><smiles>OC1[C@H](O)[C@@H](O)[C@H](O)[C@@H](O)[C@H]1O</smiles>

$58 \%$
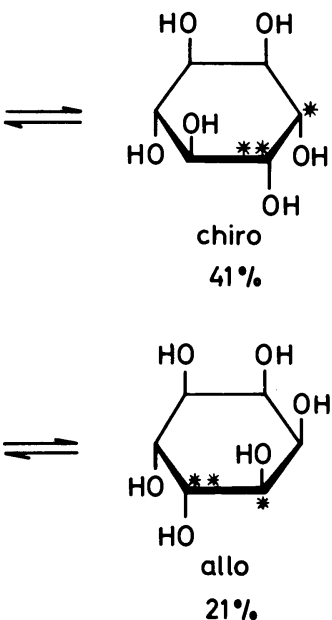

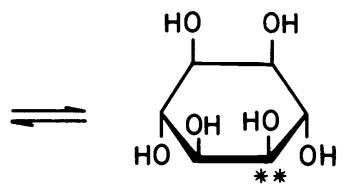

muco

$5 \%$

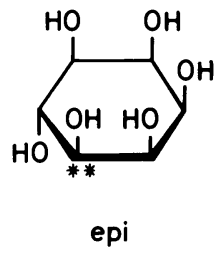

$15 \%$

Figure 17

In the inositols Angyal, Gorin and Pitman ${ }^{19}$ observed two series of isomerizations, using the acetic acid-sulphuric acid method. In the first series (Figure 17, top line) all three compounds, myo-, chiro- and mucoinositol, can be interconverted by 1,2- processes. Analogously, the compounds of the second series (Figure 17, bottom line), neo-, allo- and epi-inositol, can be interconverted by 1,2 processes. Transformations from the first to the second series should occur by 1,3- processes, and all the six isomeric inositols should be detected in the isomerization mixture. Apparently this is not the case, which demonstrates that 1,3- rearrangements are of limited importance in these six-membered rings. As mentioned before, the opposite to these findings, 1,3- rearrangements, have been observed under comparable conditions in five-membered ring systems.

The pivaloxonium salt of cyclohexane-1,3,5-triol in Figure 18 is comparatively accessible. A rearrangement with this compound can only proceed by a 1,3- process, and if such a rearrangement could occur an interesting cyclo rearrangement via six consecutive steps could be envisaged. By n.m.r. studies it was shown that most probably no fast process was at hand ${ }^{9}$.
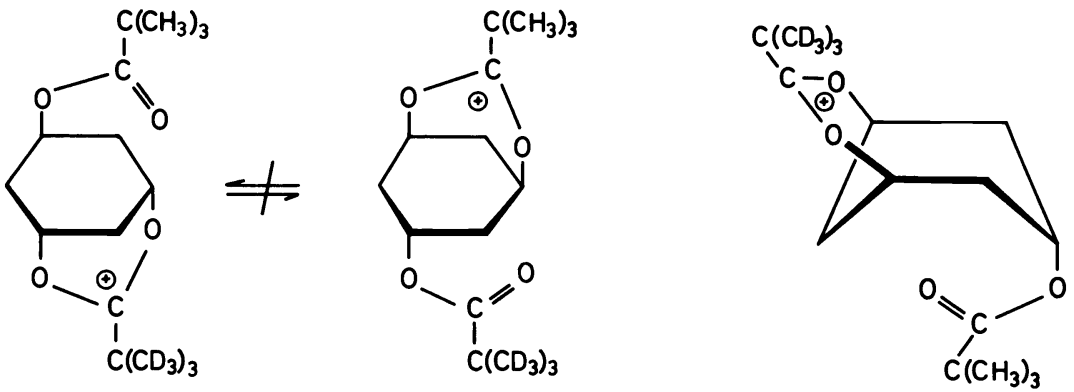

Figure 18 


\section{COMPOUNDS IN CARBOHYDRATE AND POLYOL CHEMISTRY}

Therefore the compound was labelled with one nonadeutero-tert-butyl group, as shown in Figure 18. If a detectable amount of 1,3- rearrangement were to occur with this labelled compound, the label should be distributed on both acyl groups. In the solely accessible trifluoromethane sulphonate there was found no indication for a 1,3-process operating at a considerable rate. Certainly a 1,3- rearrangement in this case would be more difficult, because a neighbouring group reaction could only occur from the unfavourable boat conformation, as shown in Figure 18 (right).

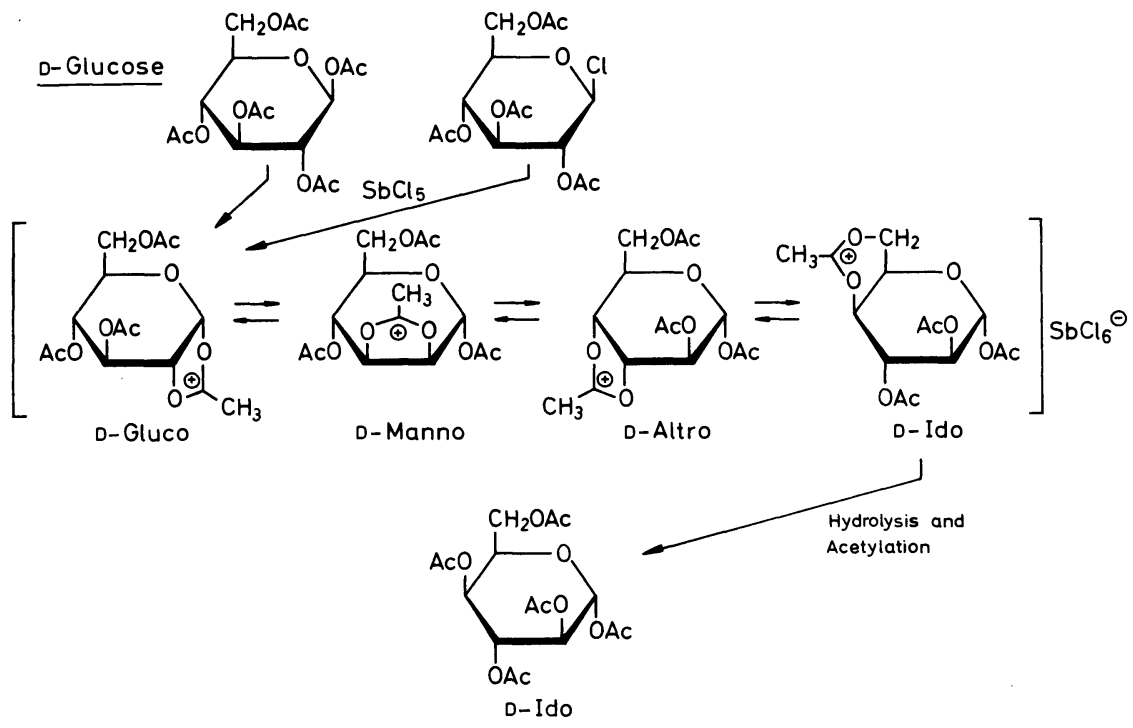

Figure 19

The basic reactions such as 1,2- and 1,3- neighbouring group reactions which have been reported above can also be accomplished in more complex polyfunctional compounds whenever the groups involved are sterically favourably situated. In those cases reaction sequences can be induced which give rise to manifold transformations of the molecule. A series of selected examples demonstrates these transformational possibilities. Furthermore, as shown later on, in addition to rearrangement reactions ring contractions have to be considered.

An impressive example, which we found some years ago in the beginning of these studies, is shown with the transformation of D-glucose to D-idose (Figure 19). A crystalline 4,6-acetoxonium salt of idopyranose (Figure 19, to the right) can be isolated in the reaction of tetra- $O$-acetyl- $\beta$-D-glucopyranosylchloride with antimony pentachloride ${ }^{20}$. As shown in Figure 19, the reaction can be explained by the primary formation of a gluco acetoxonium salt which by a fast 1,2- neighbouring group reaction rearranges to a manno ion, and this again by the same rearrangement to an altro ion. The consecutive step proceeds by a 1,3- neighbouring group reaction to yield the ido ion, which as its hexachloroantimonate represents a salt of low solubility in methylene 
chloride and causes its continuous crystallization from the equilibrium mixture ${ }^{21}$. As discussed before, the rearrangement reactions proceed rather quickly, and thus the concentration of the ido ion in solution will have to be kept at the same level by a fast re-formation at the same rate as the ido acetoxonium ion crystallizes. This is why more than 70 per cent of the gluco configuration can be transformed successfully to the ido configuration. It may be pointed out that within this reaction course the configuration is inverted at three chiral centres.

Furthermore, the pure gluco acetoxonium salt (Figure 19, to the left) can be obtained if the same reaction is performed in carbon tetrachloride at low temperatures ${ }^{21}$. In this solvent the gluco salt has extremely low solubility and is precipitated immediately, which prevents further rearrangement reactions.

In the equilibrium system of the gluco, manno, altro and ido ions of Figure 19 the amount of the single ion is determined by its thermodynamic stability. By the methods shown above the pure gluco as well as the pure ido salt can be prepared and, starting with either of these, equilibration studies in nitromethane at $-20^{\circ} \mathrm{C}$ can be performed ${ }^{21}$. The results are shown in Figure 20. To the left the distribution of ions starting with the pure gluco salt is shown. It can be observed that the amount of the gluco ion decreases slowly to 60 per cent. Starting with the pure ido salt (plots to the right), however, the amount of ido ion decreases, whereas the amount of gluco ion increases rather quickly. In both experiments a final identical equilibrium distribution of 60 per cent gluco, 21 per cent ido, 12 per cent manno and 7 per cent altro ion is obtained. Owing to its low solubility and its favourable ability to crystallize, the ido salt can be obtained and isolated in yields much higher than would be expected based on the equilibrium distribution in solution.

Such favourable conditions as are displayed with the ido-gluco equilibrium do not occur with the many acyloxonium compounds of different saccharides that we have studied. In general, an equilibrium mixture of the ions involved is obtained from which the hexachloroantimonates can be precipitated,

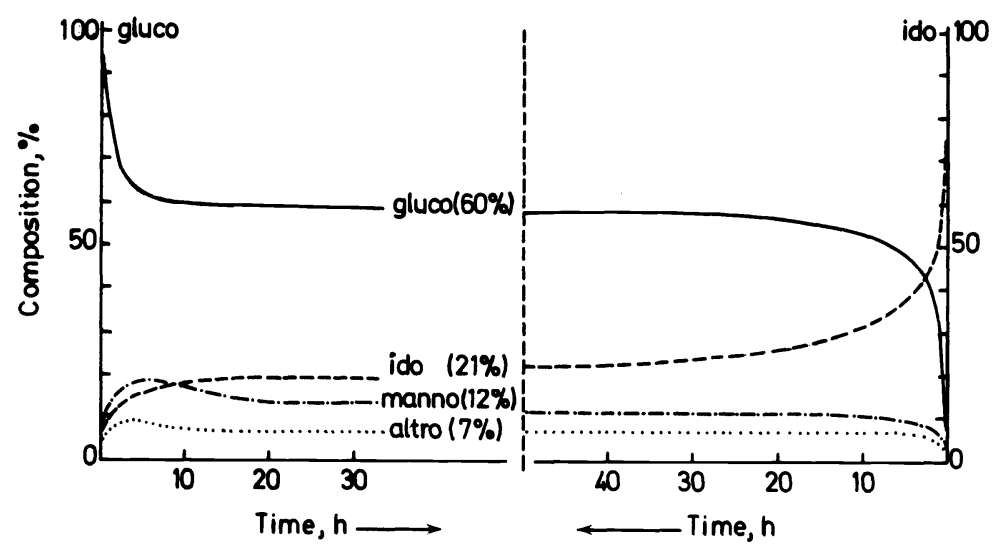

Figure 20 


\section{COMPOUNDS IN CARBOHYDRATE AND POLYOL CHEMISTRY}

containing the salts of the isomeric ions in the same ratio as in the equilibrium mixture. By hydrolysis isomeric saccharides are obtained which can only be separated by sophisticated techniques. In these cases the method must be ruled out as a synthetic procedure.

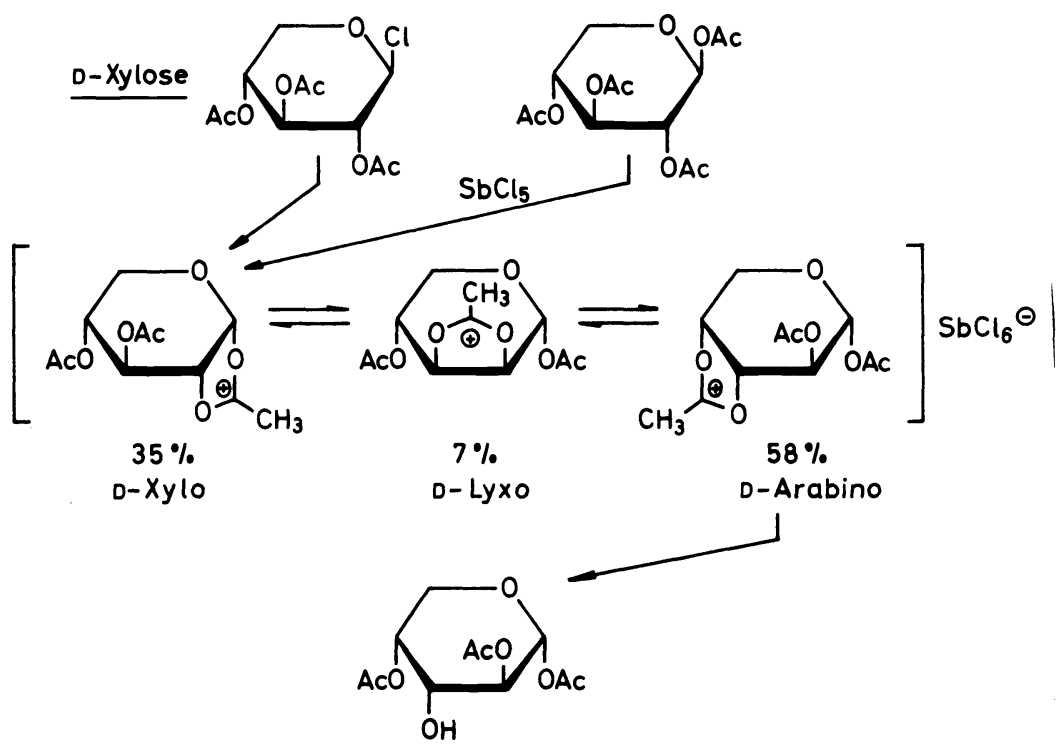

Figure 21

An example of such a case is shown in Figure 21. In preparing the acetoxonium salt from tri- $\boldsymbol{O}$-acetyl- $\beta$-D-xylopyranosylchloride, the precipitated mixture of salts contains 35 per cent xylo, 7 per cent lyxo and 58 per cent arabino salts ${ }^{22}$, from which the isomeric pentoses can be isolated only with considerable difficulty.

In order to isolate rearranged isomers, controls are necessary by which either the equilibria become more simple or they can be shifted in the desired direction. This can be effected by steric factors or by variation of the substituents or acyl residues involved in the rearrangement steps. Some selected examples are chosen to illustrate these possibilities.

In Figure 22 the acyloxonium rearrangement of D-galactose is shown. By action of antimony pentachloride on the pentaacetate or on the halogenose the galacto ion is obtained, which can rearrange to the talo ion. Within the galacto configuration the hydroxyl group at $\mathrm{C} 4$ is axial and therefore further intramolecular neighbouring group reactions are impossible. In this case only two ions are in equilibrium, one of which, the talo ion, predominates ${ }^{23}$. By hydrolysis of the salt mixture tetraacetates are obtained from which after reacetylation the easily crystallized talopyranose pentaacetate can be prepared directly ${ }^{23}$.

The example in Figure 23 shows the synthesis of the acetoxonium salt of 3-acetamido-3-deoxy-D-glucopyranose. The initially formed gluco ion can 


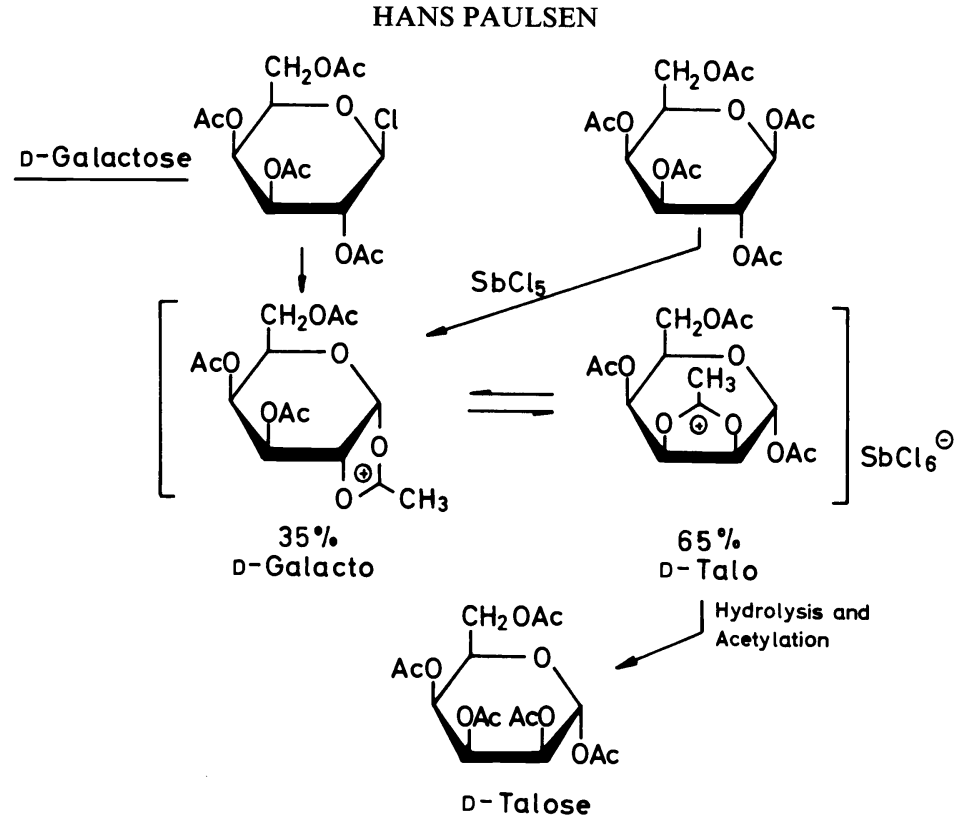

Figure 22

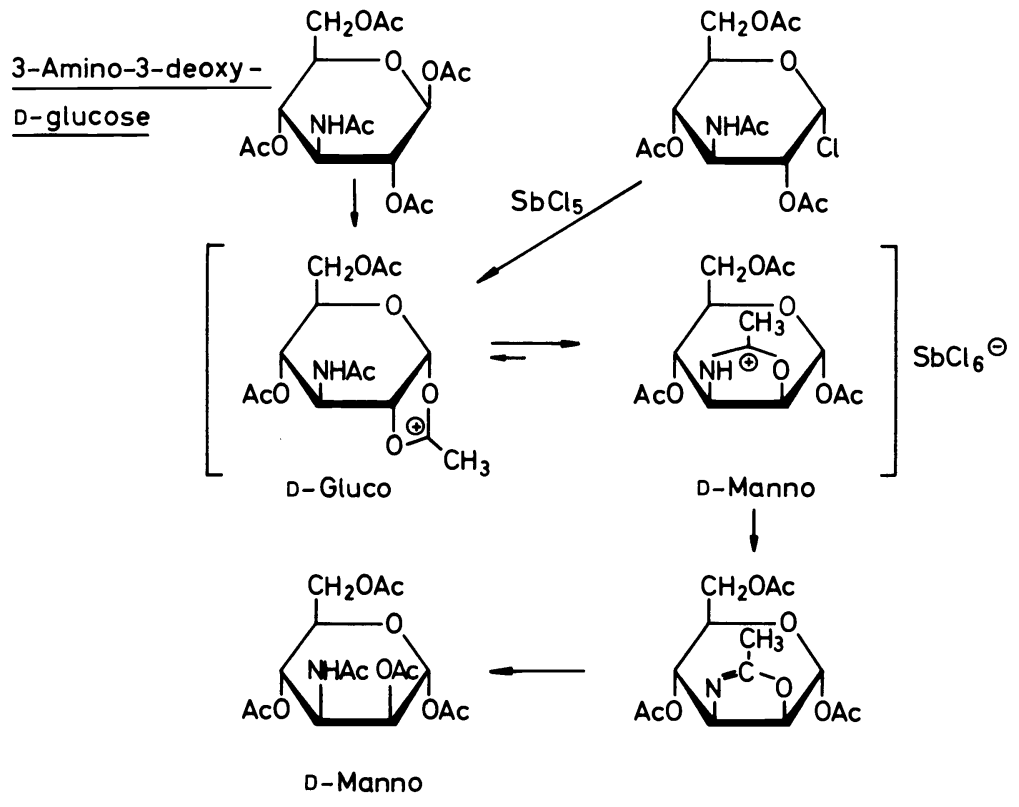

Figure 23 


\section{COMPOUNDS IN CARBOHYDRATE AND POLYOL CHEMISTRY}

rearrange to a manno oxazolinium ion. Also, in this case the rearrangement cannot proceed because the amino group is very difficult to detach; it cannot be detached by an acetoxy group in a neighbouring group reaction. An equilibrium between the acetoxonium and the oxazolinium ions appears which is shifted predominantly to the nitrogen-containing ion $^{24}$. As a consequence, the manno isomer is the only reaction product which can be isolated.

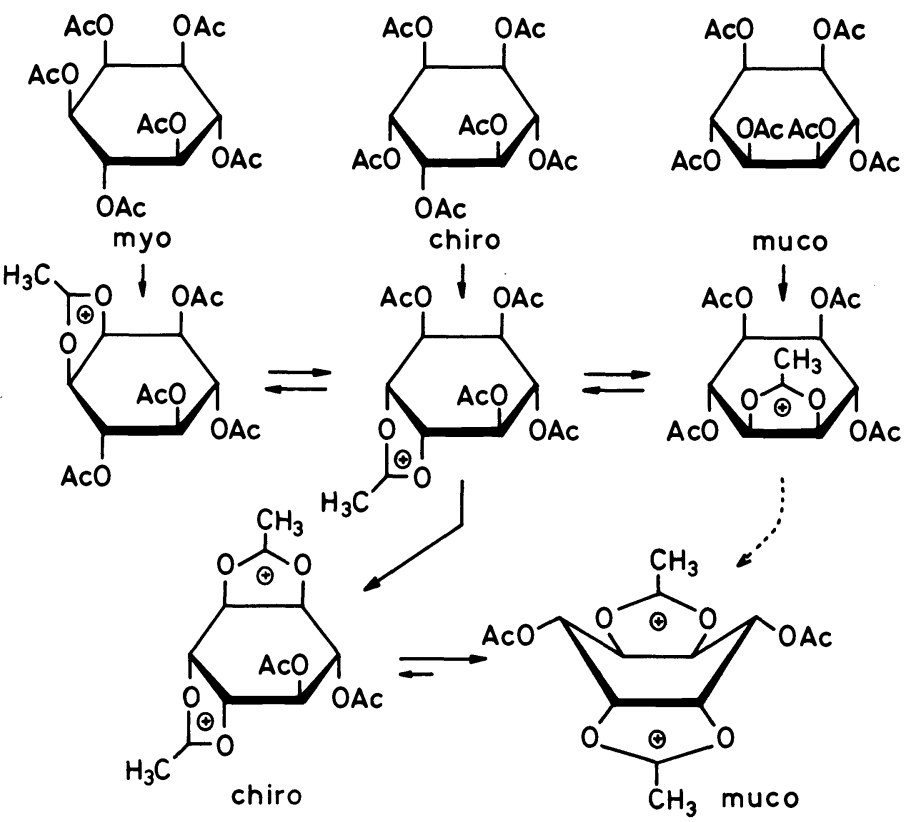

Figure 24

As a further example, in Figure 24 the reaction of myo-inositol hexaacetate with absolute hydrogen fluoride will be discussed. Some years ago Hedgley and Fletcher ${ }^{25}$ observed that myo-inositol isomerized in hydrogen fluoride and yielded muco-inositol as main product of this transformation. On the basis of a calculation of intramolecular interactions of substituents, by which just the muco isomer was shown to be the most labile ${ }^{19}$, this report was rather unusual.

A particularly stabilized derivative of muco-inositol could be the muco dication shown in Figure 24 to the right at the bottom. Here all the substituents are quasi-equatorially arranged and the ideal boat conformation is adopted. Therefore we suppose that this stable muco dication and not a muco monocation would be the final product of the isomerization. In other long-lasting reactions with hydrogen fluoride or trifluoromethane sulphonic acid several comparable dications have been observed. Indeed n.m.r. studies of the final reaction products underline the formation of a boat-like muco dication ${ }^{26}$. Because this molecule is symmetric, a particularly simple n.m.r. spectrum is 


\section{HANS PAULSEN}

observed. It shows an acetoxonium-methyl- and a normal acetoxymethylsignal, in addition to a signal of two moles of acetic acid generated in the course of the reaction, all of comparable intensity.

The n.m.r. spectroscopy of the proceeding reaction together with a product analysis give rise to the formulation of an unexpected reaction course. Initially, in hydrogen fluoride one of the cis-diol ester groupings of myoinositol hexaacetate reacts by cleavage of one mole of acetic acid to give the myo monocation. This cation cannot react further, because no other cis-diol ester grouping is available, and thus an equilibrium between the three myo, chiro and muco monocations is obtained (Figure 24, second line). Both the chiro and the muco monocations possess a cis-diol ester grouping, which with hydrogen fluoride can react with formation of a dication. The cleavage of the second mole of acetic acid from the chiro monocation is considerably faster than that from the muco monocation ${ }^{26}$. In this way the chiro dication (bottom, to the left) is increased in concentration during the intermediate phase of the reaction. In the final phase, however, the labile chiro dication will have been almost completely rearranged to the more stable muco dication. Thus, by quenching the reaction at this intermediate stage up to 70 per cent chiroinositol can be obtained by rearrangement of myo-inositol. More than 80 per cent muco-inositol can be isolated as product of the isomerization, starting with myo-inositol and carrying the reaction to the final stage ${ }^{26}$.

Instead of myo-inositol, muco- or chiro-inositol can be used as starting material and by analogy the primary formation of monocations in equilibrium with one another is observed. Further elimination of acetic acid in the chiro system leads to formation of a chiro dication which consecutively yields the muco dication. The direct formation of a muco dication from the muco monocation proceeds to secondary degree ${ }^{26}$.

In addition to 1,2- and 1,3-acyloxonium rearrangements, ring contractions of acyloxonium ions have been observed with several different systems. Supposedly, ring contractions as a third reaction possibility of acyloxonium ions have to be taken into account whenever steric conditions favour ring contraction products.

By action of hydrogen fluoride on D-arabinopyranose tetrabenzoate or D-ribopyranose tetrabenzoate the formation of an identical ring contracted ribofuranose ion (Figure 25, right) was observed by Pedersen ${ }^{27}$, if the reaction was carried out until no substantial change in the product composition occurred. In the first step the D-arabinopyranose tetrabenzoate should give rise to an arabino ion (Figure 25, top line), which by a 1,2- process should rearrange to the ribo ion and further from that to the ring contracted ribo ion. In the reaction of D-ribopyranose pentabenzoate the ring contraction should proceed with the ribo ion formed initially (Figure 25, bottom line). The way by which the ring transformations proceed cannot be understood at this stage; however, the ribofuranose ion formed should be of enhanced stability.

The action of liquid hydrogen fluoride on 3-O-methyl-D-glucopyranose tetraacetate (Figure 26), according to Pedersen ${ }^{28}$, gives rise to the fast formation of a glucopyranose monocation, which cannot undergo a 1,2rearrangement, because the 3-O-methyl group is incapable of neighbouring group reactions ${ }^{29}$. With extended reaction times transformation largely 


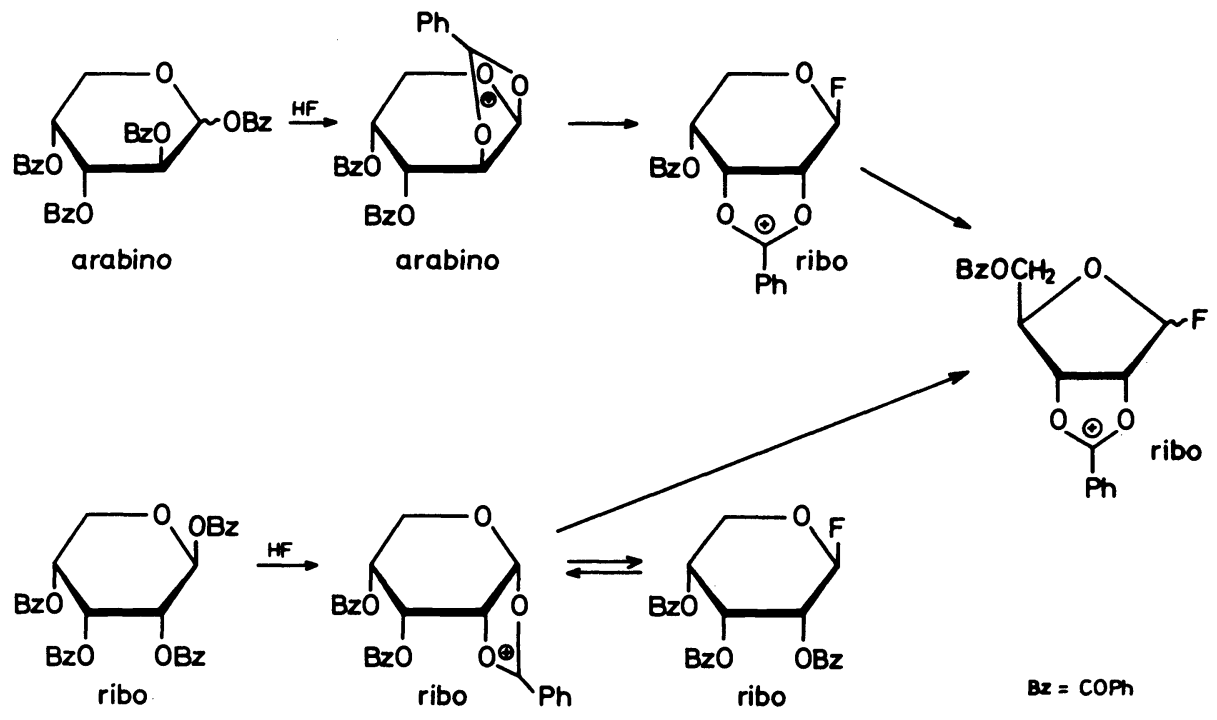

Figure 25

to a glucofuranose dication is observed (Figure 26, top right). Obviously the ring contracted dication exhibits a considerably enhanced stability related to the steric arrangement in the molecule. Surprisingly, by work-up of the liquid hydrogen fluoride solution, ring expansion to 2,4,6-tri-Oacetyl-3-O-methyl-D-glucopyranosylfluoride occurs ${ }^{28}$.

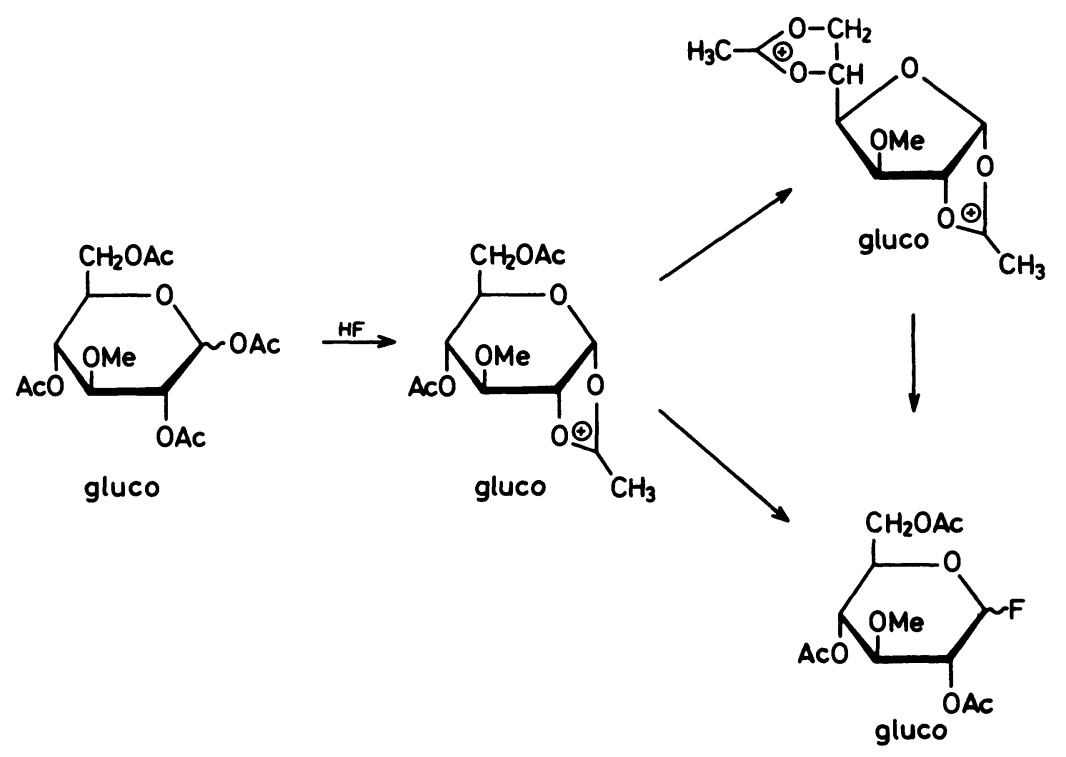

Figure 26 
We studied the action of trifluoromethane sulphonic acid on monosaccharides. With the aid of this reagent a selective introduction of acetoxonium groupings into monosaccharides should be possible by which the corresponding rearrangements could be induced. Most favourable for these studies were the triacetates of 1,6-anhydropyranoses, because in these compounds the anomeric centre is blocked, which limits secondary and further decomposition reactions.
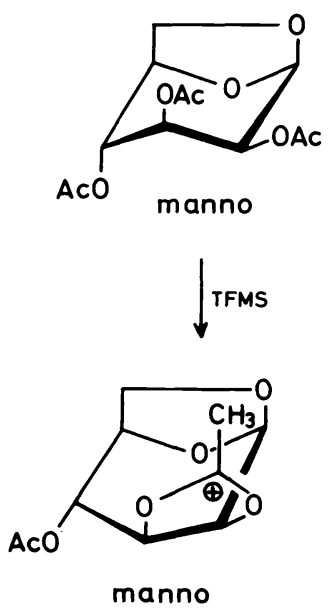
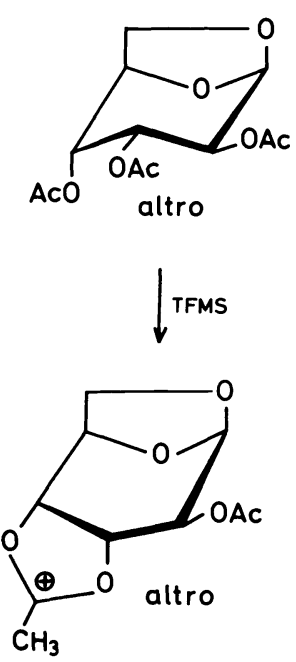

Figure 27

1,6-Anhydro-D-mannopyranose triacetate and also 1,6-anhydro-D-altropyranose triacetate react quite normally with trifluoromethane sulphonic acid (Figure 27). By a cis- reaction the manno- compound yields a manno ion; the altro compound, an altro ion ${ }^{30}$. Manno and altro ions are in equilibrium by a 1,2- acetoxonium rearrangement, and the relative amount of the former to the latter is $1: 3^{30}$, which demonstrates the slightly higher stability of the altro ion ${ }^{31}$. No matter whether the reaction is started with the mannoor the altro-triacetate, an identical equilibrium mixture of ions is obtained.

An unusual course of reaction is observed in the action of trifluoromethane sulphonic acid on 1,6-anhydro-D-talopyranose triacetate (Figure 28) ${ }^{30}$. As expected in cis- reactions, both the possible talo ions, the 2,3- and the 3,4-acetoxonium ions are formed (Figure 28, bottom line, left). In addition to this considerable amounts of ring-contracted ions occur: the talo-1,6anhydrofuranose ion (top right) and the double contracted talo-1,5-anhydrofuranose ion (bottom right). The formation of these two ions is surprising, and it has been ascertained that the ring contraction reaction proceeds with retention, and that the talo configuration in both new ions has been maintained unchanged ${ }^{30}$.

If the configuration does not change and in the ring contraction a transformation from the $\beta$ - into an $\alpha$-form has to occur, the explanation for the 

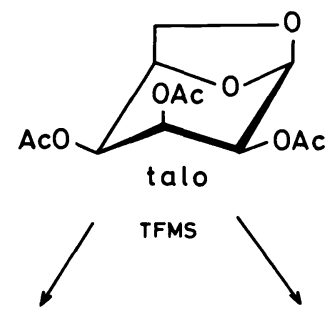

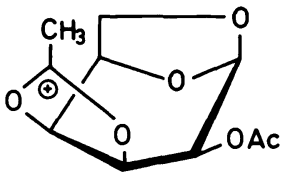

talo

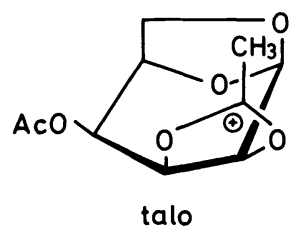

Figure 28
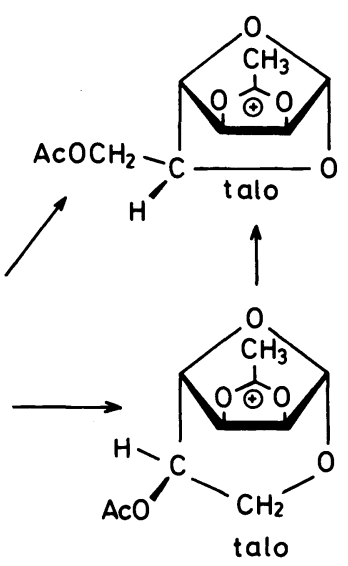

reaction course requires the use of a ring-opened intermediaı. A possible mechanism is shown in Figure 29. According to that, a ring-opened intermediate is formed via a protonation at the ring oxygen (bottom line). This can recombine to yield the starting product or undergo the acyl migration of an acetyl group from $\mathrm{O}-4$ to $\mathrm{O}-5^{31}$. By recombination of $4-\mathrm{OH}$ with $\mathrm{Cl}$ the ring-contracted talo ion (top right) is obtained. Possibly orthoester-like intermediates can be consecutive intermediates in this reaction course. These may allow for a somewhat tight cationic form which is able to recombine, as is demanded by the results.

Accordingly, the protonation of the 1,6-anhydro ring oxygen can be considered, leading to an intermediate with an open 1,6-anhydro ring, as shown in Figure 30. By recombination the starting material is formed again, whereas by an acyl migration and a secondary recombination the twofold

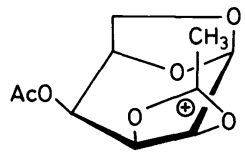

talo

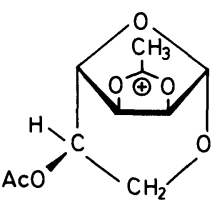

talo
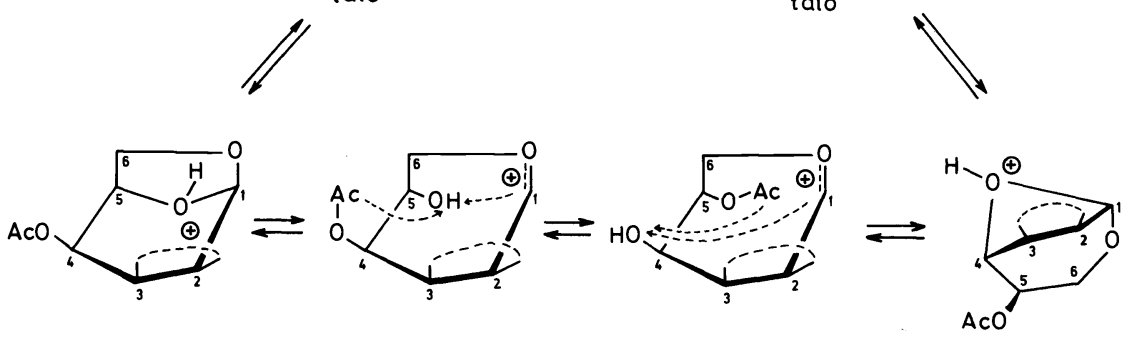

Figure 29 


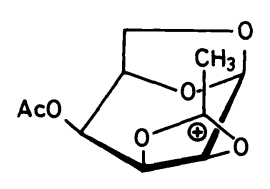

talo

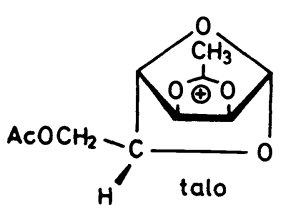

$\mathbb{1}$

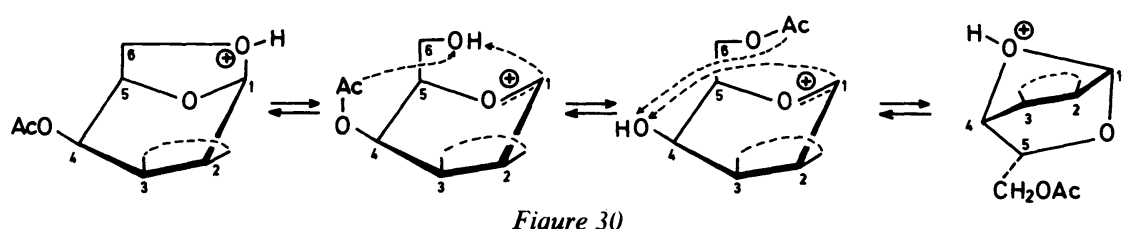

Figure 30

contracted talo ion (top right) could be obtained ${ }^{30}$. In this way, that ion can be formed directly from the 1,6-anhydro-talopyranose ion. Furthermore, it can be considered that by a completely analogous reaction course the mutual transformation proceeds between the 1,6-anhydro-talofuranose ion and the 1,5-anhydro-talofuranose ion ${ }^{30}$.

Obviously the indicated reaction steps should be reversible, which implies that in the system under discussion there exists an equilibrium between all the ions involved, including the ring-contracted ions. Because the amount of ions is related to their stability, it can be concluded that the furanose ions in the talo system are of comparable stability to the pyranose ions. Finally, the problem of the stereochemistry of furanose ions remains to be discussed.
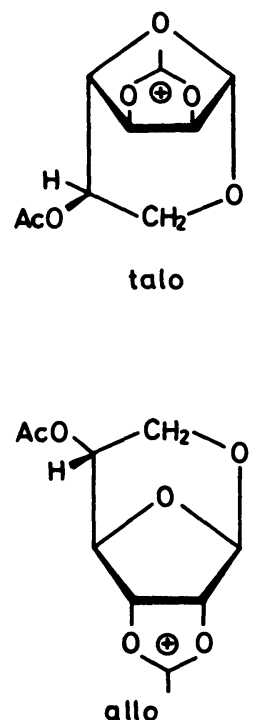
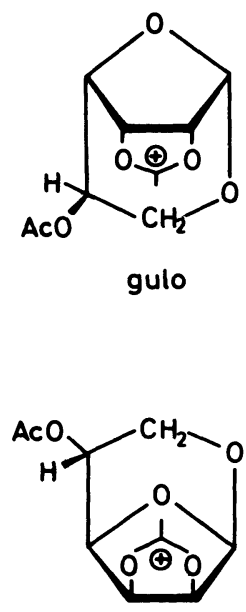

manno

Figure 31 
In Figure 31 the four possible isomeric furanose ions are collated. The gluco, galacto, altro and ido configurations have been omitted, because none of them exhibits a cis- arrangement at $\mathrm{C} 2-\mathrm{C} 3$. In the tricyclic system of the gulo and the manno form (right) the terminal rings are in endo, and in the talo and allo form (left) in exo- position to one another, as shown in Figure 31. Thus the former two ions should be of lower and the latter two of enhanced stability. From this consideration a prediction can be made: from all the isomeric 1,6-anhydro-hexopyranose triacetates only the allo and the talo isomers can be expected to contribute to a certain amount of ring-contracted products in the isomerization mixture with trifluoromethane sulphonic acid.
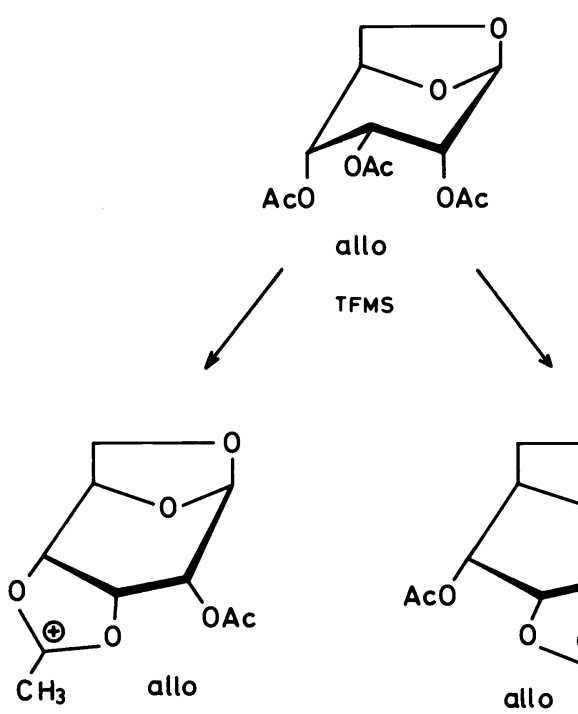

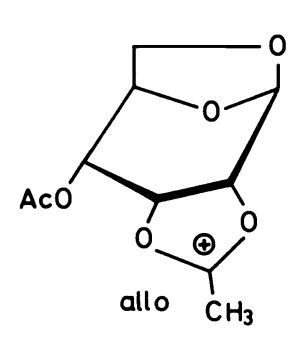

Figure 32

Figure 32
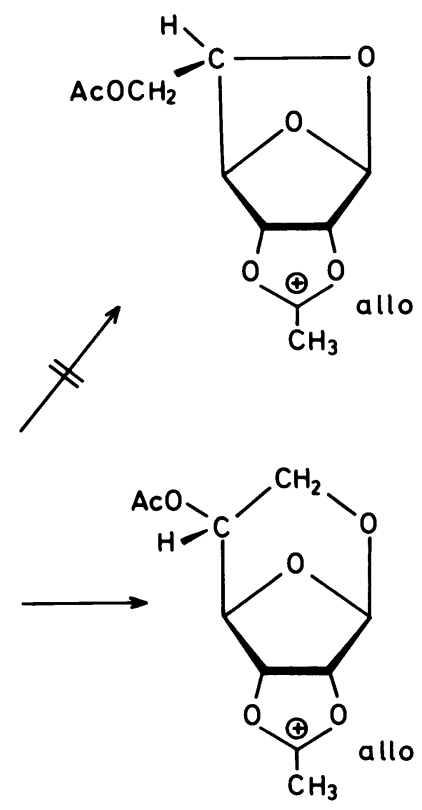

As demonstrated in Figure 32, this is indeed the case. By cis- reaction of 1,6-anhydro-allopyranose triacetate, both of the expected cations, the 2,3acetoxonium and the 3,4-acetoxonium ion are formed. Furthermore, a considerable amount of onefold ring-contracted allo-1,6-anhydrofuranose ion (bottom right) is observed, which, according to the former consideration, displays a stability comparable to that of pyranose ions. Not observed, however, is the twofold contracted allo-1,5-anhydrofuranose ion (top right). This is more unstable and it seems reasonable to compare the steric conditions of the 1,5-anhydrofuranoses.

In Figure 33 the two ions under consideration are shown together. It can be noted that the bicyclic terminal rings in both ions adopt the more favourable exo- arrangement. In the talo ion (left) the large $\mathrm{CH}_{2} \mathrm{OAc}$ group is bound in exo- position to the other ring, whereas in the allo ion (right) it adopts the unfavourable endo- position with respect to the furanose ring. 

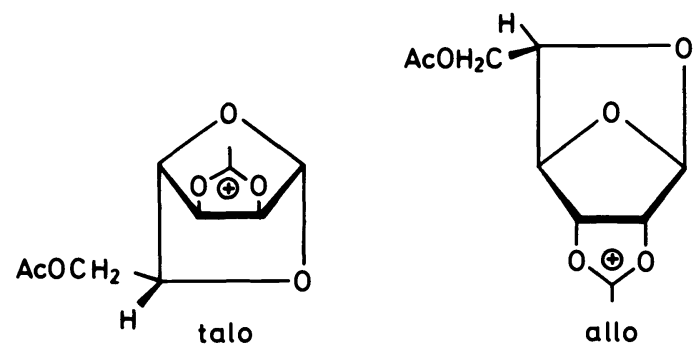

Figure 33

Obviously this additional steric interaction causes a destabilization of the allo ion, so that no detectable amount will be found in the equilibrium. The more favourable talo ion, however, is found in considerable amounts in isomerization experiments with 1,6-anhydro-talopyranose.

\section{REFERENCES}

1 G. A. Olah, Angew. Chem. 85, 183 (1973); Angew Chem. Intern. Ed. Engl. 12, 183 (1973).

2 H. Meerwein, K. Bodenbenner, P. Borner, F. Kunert and K. Wunderlich. Ann. Chem. 632, 38 (1960).

3 H. Meerwein, V. Hederich, H. Morschel and K. Wunderlich, Ann. Chem. 635, 1 (1960).

4 H. Paulsen, Advanc. Carbohydr. Chem. Biochem. 26, 127 (1971).

5 H. Paulsen and H. Behre, Chem. Ber. 104, 1264 (1971).

6 C. Pedersen, Tetrahedron Letters, 511 (1967).

7 H. Paulsen and H. Meyborg, Tetrahedron Letters, 3973 (1972).

8 I. Lundt and C. Pedersen, Acta Chem. Scand. 26, 1938 (1972).

9 H. Paulsen and H. Meyborg, Chem. Ber., in press (1975).

$10 \mathrm{H}$. Paulsen and H. Höhne, unpublished results.

11 H. Paulsen and R. Dammeyer, Chem. Ber. 106, 2324 (1973).

12 H. Paulsen and R. Dammeyer, unpublished results.

13 H. Paulsen and H. Behre, Chem. Ber. 104, 1281 (1971).

14 S. Jacobsen, I. Lundt and C. Pedersen, Acta Chem. Scand. 27, 453 (1973).

15 H. Paulsen and H. Behre, Chem. Ber. 104, 1299 (1971).

16 H. Paulsen, H. Meyborg and H. Behre, Angew. Chem. 81, 907 (1969); Angew. Chem. Intern. Ed. Engl. 8, 888 (1969).

17 H. Paulsen and O. Brauer, unpublished results.

18 S. J. Angyal and B. M. Luttrell, Austral. J. Chem. 23, 1831 (1970).

19 S. J. Angyal, P. A. L. Gorin and M. E. Pitman, J. Chem. Soc. 1807 (1965).

20 H. Paulsen, W.-P. Trautwein, F. Garrido-Espinosa and K. Heyns, Chem. Ber. 100, 2822 (1967).

21 H. Paulsen and C.-P. Herold, Chem. Ber. 103, 2450 (1970).

22 H. Paulsen, C.-P. Herold and F. Garrido-Espinosa, Chem. Ber. 103, 2463 (1970).

23 F. Garrido-Espinosa, W.-P. Trautwein and H. Paulsen, Chem. Ber. 101, 191 (1968).

24 H. Paulsen and C.-P. Herold, Chem. Ber. 104, 1311 (1971).

25 H. J. Hedgley and H. G. Fletcher, Jr, J. Amer. Chem. Soc. 84, 3726 (1962).

26 H. Paulsen and H. Höhne, Chem. Ber. 105, 3445 (1972).

27 C. Pedersen, Acta Chem. Scand. 22, 1888 (1968).

28 C. Pedersen, unpublished results.

29 S. Jacobsen, S. R. Jensen and C. Pedersen, Acta Chem. Scand. 26, 1561 (1972).

30 P. L. Durette and H. Paulsen, Chem. Ber. 107, 937, 951 (1974); Carbohyd. Res. 35, 221 (1974).

31 K. Bock and C. Pedersen, Acta Chem. Scand. 27, 2701 (1973); Carbohyd. Res. 29, 331 (1973). 